\title{
Comparison of the combination of propofol and etomidate versus propofol or etomidate alone for induction of general anesthesia: a double-blind, randomized controlled trial
}

\author{
Type \\ Research paper

\section{Keywords} \\ propofol, Hemodynamics, etomidate, Induction of general anesthesia, processed \\ electroencephalography
}

\begin{abstract}
Introduction

Hemodynamic fluctuation during the induction of general anesthesia is a common event and adversely affect patients' outcomes. The aim of this study is to investigate the impacts of different anesthesia induction agents: propofol, etomidate, and propofol-etomidate combination on patient hemodynamics and processed electroencephalography (EEG).

Material and methods

Seventy-five patients undergoing elective non-cardiac surgery were randomly assigned to three groups of anesthesia induction agents: the group P received $2 \mathrm{mg} / \mathrm{kg}$ propofol, the group $E$ received $0.3 \mathrm{mg} / \mathrm{kg}$ etomidate, and the group PE received the combination of $1 \mathrm{mg} / \mathrm{kg}$ propofol plus $0.15 \mathrm{mg} / \mathrm{kg}$ etomidate. Hemodynamic variables and processed EEG were measured during induction.
\end{abstract}

Results

Heart rate (HR) was significantly increased at intubation and 1 min after intubation compared with baseline in all three groups. Mean arterial pressure (MAP) decreased significantly after induction, at 5 , and $10 \mathrm{~min}$ after intubation in group $P(79.1 \pm 12.6,77.0 \pm 14.2,76.6 \pm 11.4$ versus $93.2 \pm 9.9 \mathrm{mmHg}$; all $\mathrm{P} \square 0.001)$. MAP increased significantly at intubation and $1 \mathrm{~min}$ after intubation in group $\mathrm{E}$ (104.7 $\pm 13.0,103.8 \pm 12.8$ versus $92.9 \pm 10.2 ; P \square 0.001, P=0.001$ respectively). The incidence of myoclonus was lower in groups $\mathrm{PE}(4.0 \%)$ and $\mathrm{P}(4.0 \%)$ compared with that in group $\mathrm{E}(24.0 \%)$ $(\mathrm{P}=0.033)$. The incidence of pain at injection was higher in group $\mathrm{P}(28.0 \%)$ than that in groups $\mathrm{PE}$ and $E(4.0 \%$ and $0.0 \%)(P=0.025)$.

Conclusions

The combination of propofol and etomidate used during induction of anesthesia provided a more stable BP profile, less pain at site of injection, and decreased myoclonic movements compared with propofol or etomidate alone. 
Comparison of the combination of propofol and etomidate versus propofol or etomidate alone for induction of general anesthesia: a double-blind, randomized controlled trial

Yun $\mathrm{Li}^{1,2}$, Wenze $\mathrm{Lu}^{2}$, David $\mathrm{Li}^{2}$, Jon Zhou ${ }^{2}$, Richard L. Applegate, $\mathrm{II}^{2}$, Hong Liu ${ }^{2}$

Running title: Combination of propofol and etomidate for induction

Author Affiliations: ${ }^{1}$ Department of Anesthesiology, the Second Affiliated Hospital of Anhui Medical University, Hefei, Anhui, China, ${ }^{2}$ Department of Anesthesiology and Pain Medicine, University of California Davis Health, Sacramento, CA University of California Davis Health, Sacramento, CA

\section{Correspondence to:}

Hong Liu, MD, FASE

Professor

Department of Anesthesiology and Pain Medicine

University of California Davis Health

4150 V Street, Suite 1200

Sacramento, CA 95817

Tel: 916-734-5031

Fax: 916-734-7980

E-mail: hualiu@ucdavis.edu 


\section{Abstract}

Introduction: Hemodynamic fluctuation during the induction of general anesthesia is a common event and adversely affects patients' outcomes. The aim of this study is to investigate the impacts of different anesthesia induction agents: propofol, etomidate, and propofol-etomidate combination on patient hemodynamics and processed electroencephalography (EEG).

Material and Methods: Seventy-five patients undergoing elective non-cardiac surgery were randomly assigned to three groups of anesthesia induction agents: the group $\mathrm{P}$ received $2 \mathrm{mg} / \mathrm{kg}$ propofol, the group E received $0.3 \mathrm{mg} / \mathrm{kg}$ etomidate, and the group PE received the combination of $1 \mathrm{mg} / \mathrm{kg}$ propofol plus $0.15 \mathrm{mg} / \mathrm{kg}$ etomidate. Hemodynamic variables and processed EEG were measured during induction.

Results: Heart rate (HR) was significantly increased at intubation and $1 \mathrm{~min}$ after intubation compared with baseline in all three groups. Mean arterial pressure (MAP) decreased significantly after induction, at 5 , and 10 min after intubation in group $\mathrm{P}$ (79.1 $\pm 12.6,77.0 \pm 14.2,76.6 \pm 11.4$ versus $93.2 \pm 9.9 \mathrm{mmHg}$; all $P<0.001)$. MAP increased significantly at intubation and $1 \mathrm{~min}$ after intubation in group E (104.7 \pm 13.0 , $103.8 \pm 12.8$ versus $92.9 \pm 10.2 ; P<0.001, P=0.001$ respectively). The incidence of myoclonus was lower in groups PE (4.0\%) and P (4.0\%) compared with that in group $\mathrm{E}(24.0 \%)(P=0.033)$. The incidence of pain at injection was higher in group $\mathrm{P}(28.0 \%)$ than that in groups PE and $\mathrm{E}(4.0 \%$ and $0.0 \%)(P=0.025)$.

Conclusions: The combination of propofol and etomidate used during induction of anesthesia provided a more stable BP profile, less pain at site of injection, and decreased 
myoclonic movements compared with propofol or etomidate alone.

Keywords: propofol; etomidate; induction of general anesthesia; hemodynamics; processed electroencephalography; myoclonus; pain at injection 


\section{Introduction}

Induction of anesthesia is one of the most critical steps of general anesthesia (GA). Hemodynamic instability often occurs during GA induction, especially for high-risk patients [1-3]. Conversely, laryngoscopy and endotracheal intubation are noxious stimuli eliciting unwanted hemodynamic responses such as hypertension, tachycardia and arrhythmias $[4,5]$. Therefore, it is critical to identify the optimal induction agent to maintain hemodynamic stability during induction of GA.

Etomidate and propofol are commonly used induction agents which have similar rapid onset and short duration of action $[6,7]$. However, propofol and etomidate have different advantages and adverse effects. Propofol has been associated with injection pain, significant hemodynamic change (hypotension) during induction, and less postoperative nausea and vomiting (PONV) [8-11]. Etomidate has been associated with less pain during induction, and more stable hemodynamic, with increased myoclonic movements at induction and PONV incidence [12-15]. In consideration of potential complementary effects of propofol and etomidate, many studies have assessed the benefits of administering an etomidate and propofol combination during endoscopic procedures $[16,17]$. Given limited publications available regarding the hemodynamic, pain at injection site, myoclonic movements and PONV of etomidate and propofol combinations on GA induction, it is important to provide more clinical data and address the question of whether etomidate plus propofol is better than propofol or etomidate alone for GA induction. In the current study, we aimed to compare hemodynamic, pain at injection site, myoclonic movements and PONV of etomidate plus propofol versus 
propofol or etomidate alone during GA induction and in the postoperative period. 


\section{Methods}

The study protocol was approved by the Investigational Review Board of University of California, Davis and registered at ClinicalTrials.gov (http://www.clinicaltrials.gov NCT03820388). Written informed consent was obtained from each patient. The inclusion criteria were patients aged $>18$ years old scheduled for elective non-cardiac surgery, and with an American Society of Anesthesiologists (ASA) status of 2 or 3 . The exclusion criteria were adults unable to provide informed consent, pregnant women, prisoners, Mallampati class 4, body mass index (BMI) equal or greater than $40 \mathrm{~kg} / \mathrm{m}^{2}$, severe cardiopulmonary or liver disease, hypotension, shock, and allergy to propofol or etomidate.

No preoperative sedatives or opioids were administered. Upon arrival to the preoperative area, peripheral intravenous (I.V.) access was established by inserting an 18 or 20-gauge venous cannula into the forearm. Before induction of GA, all patients received ASA standard monitoring, including pulse oximetry, electrocardiogram, noninvasive blood pressure (BP), and end-tidal carbon dioxide. In addition, electroencephalography (EEG), spectral edge frequency (SEF) and patient state index (PSI) (SedLine ${ }^{\circledR}$ Brain Function Monitor; Masimo Corporation, Irvine, CA) were used to monitor the depth of anesthesia.

Patients were randomized into 3 groups by a computerized random-number generator with respect to the anesthetic agent used for induction of GA. Anesthetic agents were prepared separately by a member of the research team who was not involved in the induction of GA. The clinical care team were blinded to the treatment allocation. The 
propofol group (group P) received $2 \mathrm{mg} / \mathrm{kg}$ of propofol I.V., the etomidate group (group E) received $0.3 \mathrm{mg} / \mathrm{kg}$ of etomidate I.V., and the propofol plus etomidate group (group PE) received a combination of $1 \mathrm{mg} / \mathrm{kg}$ of propofol plus $0.15 \mathrm{mg} / \mathrm{kg}$ of etomidate I.V. based on ideal body weight. All patients received I.V. injection of $100 \mu \mathrm{g}$ of fentanyl prior to injection of the assigned induction agent. The induction agent was then administered via manual hand bolus over 30 seconds. After palpebral reflex was lost, 1 $\mathrm{mg} \mathrm{kg}{ }^{-1}$ of rocuronium was given, and 1 min later the patient was orotracheally intubated. After intubation, GA was maintained with sevoflurane and $80 \%$ oxygen to maintain SEF between 8-15 Hertz (Hz). All patients were also given $4 \mathrm{mg}$ of I.V. ondansetron at the end of surgery.

Blood pressure, HR, SEF, and PSI were recorded at baseline (T0), induction (T1), intubation (T2), and 1, 3, 5, and 10 min after intubation (T3-T6). The time from the start of induction to palpebral reflex loss and intubation were recorded for each patient. Pain at injection was assessed via a 4-point grading scale ( 0 : no pain communicated, 1 : complains of pain, 2: withdrawal to pain, 3: both verbal complaint and withdrawal of arm). The intensity of myoclonic movement was assessed as follows: 0 , no myoclonus; 1, mild myoclonus (short movements of a body segment, e.g. a finger or a wrist only); 2, moderate myoclonus (mild movements of two different muscles, e.g. face and leg); 3, severe myoclonus (intense clonic movements in two or more muscle groups, fast adduction of a limb)[12]. The incidence and degree of pain at injection and myoclonic movements during injection of induction agents were recorded. In addition, the occurrences of PONV in the post anesthesia care unit (PACU) were recorded. The 
primary outcomes were hemodynamics. The second outcomes included PSI, SEF, the time from the start of induction to palpebral reflex loss and intubation, pain at injection, myoclonic movements and PONV.

\section{Statistical analysis}

Sample size calculations were based on our pilot study, and we found MAP to be $80.1( \pm 10.3) \mathrm{mmHg}, 90.3( \pm 10.4) \mathrm{mmHg}, 91.0( \pm 11.6) \mathrm{mmHg}$ in group P, PE and E, respectively at induction. Using PASS 15.0 software, a sample size of 20 patients per group would be needed to detect statistically significant differences with the power of 0.9 and the alpha level of 0.05 . Considering a possible $20 \%$ dropout rate, 25 patients per group were recruited for the study.

Parametric values were expressed as mean $\pm \mathrm{SD}$, or percentages of the total number of patients $(\%)$. Categorical data were analyzed using $\chi^{2}$ or Fisher's exact test as appropriate. The hemodynamic parameters among the three groups were compared using the general linear model (GLM). We also considered time of evaluation as a within-subject factor, and the intervention state as a between-subject factor. The time groups (interaction terms) were considered group differences among the three groups in their responses over time. We used Mauchly's sphericity test for compound symmetry assumption. Differences in hemodynamic variables between the three groups at different time points were compared by post hoc Bonferroni test. $P<0.05$ was considered statistically significant. All statistical analyses were performed with SPSS 22.0 (SPSS; Chicago, IL, USA). 


\section{Results}

The flow diagram of this study is shown in Figure 1. Seventy-nine patients who were scheduled to undergo elective surgical procedures were assessed for the study. Four patients were excluded based on criteria. Seventy-five patients were randomized and included in the final analysis. There were no significant differences among the three groups in patient characteristics (Table 1).

Hemodynamic data and processed EEG values measured during the study are presented in Figure 2 and 3. There were no statistically significant differences within the groups regarding hemodynamics and processed EEG values at baseline.

There was a significant time effect (within-subject effects) $(P<0.001)$ for HR, while there were no statistically significant effects of group or group-by-time interaction. HR was significantly increased at intubation and $1 \mathrm{~min}$ after intubation compared with baseline in the three groups (propofol plus etomidate group: $F=19.34$; $D f=-11.9$, $P=0.001 ; \mathrm{Df}=-10.2, P=0.006 ;$ etomidate group: $\mathrm{F}=19.34 ; \mathrm{Df}=-14.1, P=0.002 ; \mathrm{Df}=-12.2$, $P=0.018 ;$ propofol group: $\mathrm{F}=16.02 ; \mathrm{Df}=-11.2, \quad P<0.001 ; \mathrm{Df}=-10.9, \quad P=0.001)$. However, there was no significant difference in HR among the three groups at all points during induction and intubation.

There were significant time effects (within-subject effects) and group effects for systolic BP (SBP), diastolic BP (DBP), and mean arterial pressure (MAP) $(P<0.01)$. Furthermore, a significant effect of group-by-time interaction was also present for SBP, DBP and MAP $(P<0.05, P<0.05$, and $P<0.01$, respectively). In the propofol group, the SBP, DBP, and MAP were significantly decreased at induction and 5, 10 min after 
intubation compared with baseline (SBP: $\mathrm{F}=19.34 ; \mathrm{Df}=21.0, P<0.001 ; \mathrm{Df}=20.5, P<$ 0.001; $\mathrm{Df}=21.2, P<0.001 ; \mathrm{DBP}: \mathrm{F}=13.62 ; \mathrm{Df}=10.8, P=0.001 ; \mathrm{Df}=14.2, P<0.001$; Df $=14.4, P<0.001 ;$ MAP: $\mathrm{F}=17.92 ; \mathrm{Df}=14.2, P<0.001 ; \mathrm{Df}=16.2, P<0.001 ; \mathrm{Df}$ =16.7, $P<0.001)$. There were significant increases of SBP, DBP and MAP at intubation and $1 \mathrm{~min}$ after intubation than at baseline in the etomidate group (SBP: $\mathrm{F}=13.62 ; \mathrm{Df}=-15.2, P=0.002 ; \mathrm{Df}=-15.8, P=0.005 ; \mathrm{DBP} ; \mathrm{F}=9.70 ; \mathrm{Df}=-9.9, P=0.004$; $\mathrm{Df}=-8.4, P=0.017 ; \mathrm{MAP}: \mathrm{F}=14.73 ; \mathrm{Df}=-11.7, P<0.001 ; \mathrm{Df}=-10.9, P=0.001)$. There were no significant differences in SBP, DBP and MAP in the propofol plus etomidate group. Compared with the propofol group, there were significantly higher SBP, DBP and MAP at induction (SBP: $\mathrm{F}=6.84, \mathrm{Df}=16.7, P=0.014 ; \mathrm{DBP}: \mathrm{F}=5.56, \mathrm{Df}=9.8$, $P=0.012$; MAP: $\mathrm{F}=8.04, \mathrm{Df}=12.1, P=0.005)$ in the propofol plus etomidate group. $\mathrm{SBP}$ and MAP were significantly increased at induction and 1,3, 5, 10 min after intubation in the etomidate group compared with the propofol group (SBP: $F=6.84, \mathrm{Df}=17.4$, $P=0.001 ; \mathrm{F}=5.79, \mathrm{Df}=21.4, P=0.009 ; \mathrm{F}=8.34, \mathrm{Df}=22.2, P=0.002 ; \mathrm{F}=6.24, \mathrm{Df}=21.3$, $P=0.002 ; \mathrm{F}=3.52, \mathrm{Df}=12.5, P=0.029 ; \mathrm{MAP}: \mathrm{F}=8.04, \mathrm{Df}=12.3, P=0.004 ; \mathrm{F}=6.06$, $\mathrm{Df}=13.4, P=0.014 ; \mathrm{F}=5.43, \mathrm{Df}=12.8, P=0.017 ; \mathrm{F}=6.80, \mathrm{Df}=16.1, P=0.002 ; \mathrm{F}=4.53$, $\mathrm{Df}=11.0, P=0.012$ ). Lastly, DBP was higher at induction, and 5, and $10 \mathrm{~min}$ after intubation in the etomidate group than that in the propofol group $(\mathrm{F}=5.56, \mathrm{Df}=9.9$, $P=0.049 ; \mathrm{F}=5.26, \mathrm{Df}=13.6, P=0.015 ; \mathrm{F}=3.74, \mathrm{Df}=10.2, P=0.026$ ) (Figure 2).

The time course of percentage changes in HR, SBP, DBP, and MAP with respect to baseline is shown in Figure 4. Intragroup comparisons showed that there were no statistically significant differences in the percent change in HR during induction and 
intubation. There were significantly higher percent changes in SBP at induction and 1,3,5 min after intubation $(\mathrm{F}=8.37, \mathrm{Df}=11.9, P=0.002 ; \mathrm{F}=4.74, \mathrm{Df}=15.5, P=0.01$; $\mathrm{F}=6.43, \mathrm{Df}=15.8, P=0.002 ; \mathrm{F}=7.51, \mathrm{Df}=15.4, P=0.001)$, and percent changes in DBP and MAP at induction and after intubation in the etomidate group compared to the propofol group (\% changes in DBP: $\mathrm{F}=7.94, \mathrm{Df}=14.5, P=0.002 ; \mathrm{F}=5.95, \mathrm{Df}=15.1$, $P=0.005 ; \mathrm{F}=4.42, \mathrm{Df}=12.9, P=0.016 ; \mathrm{F}=7.28, \mathrm{Df}=19.7, P=0.001 ; \mathrm{F}=4.59, \mathrm{Df}=14.9$, $P=0.012 ; \%$ changes in MAP: $\mathrm{F}=12.39, \mathrm{Df}=13.3, P<0.001 ; \mathrm{F}=7.05, \mathrm{Df}=15.2, P=0.002$; $\mathrm{F}=6.85, \mathrm{Df}=14.2, P=0.001 ; \mathrm{F}=9.66, \mathrm{Df}=17.6, P<0.001 ; \mathrm{F}=4.66, \mathrm{Df}=11.6, P=0.012)$. Lastly, there were significantly higher percent changes in SBP at induction $(\mathrm{F}=8.37$, $\mathrm{Df}=12.1, P=0.002$ ), and increased percent changes in DBP and MAP at induction and 1,5 min after intubation in the propofol plus etomidate group compared to the propofol group (\% changes in DBP: $\mathrm{F}=7.94, \mathrm{Df}=13.7, P=0.004 ; \mathrm{F}=5.95, \mathrm{Df}=12.2, P=0.033$; $\mathrm{F}=7.28, \mathrm{Df}=14.0, P=0.031 ; \%$ changes in MAP: $\mathrm{F}=12.39, \mathrm{Df}=12.8, P<0.001 ; \mathrm{F}=7.05$, $\mathrm{Df}=11.2, P=0.028 ; \mathrm{F}=9.66, \mathrm{Df}=11.8, P=0.015)$.

There was a significant time effect (within-subject effects) $(P<0.001)$ for PSI, but there were no statistically significant effects of group and group-by-time interaction. The values of PSI were significantly lower during induction and intubation relative to baseline in all three groups (propofol plus etomidate group: $\mathrm{F}=212.80, P<0.01$; etomidate group: $\mathrm{F}=251.79, P<0.01$; propofol group: $\mathrm{F}=243.01, P<0.01)$. There were no significant differences in the values of PSI, SEFL, and SEFR (SEF left and right) at all points among three groups (Figure 3). There were no significant differences among three groups with respect to the time from start of the induction agent injection to 


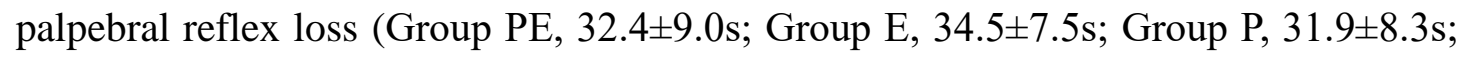
$P=0.524$ ), nor time until orotracheal intubation (Group PE, 93.1 \pm 9.5 s; Group E, 95.1 $\pm 8.9 \mathrm{~s} ;$ Group P, $92.4 \pm 9.6 \mathrm{~s} ; P=0.556)$.

The incidences of myoclonus in the propofol plus etomidate group (4.0\%) and the propofol $(4.0 \%)$ were significantly lower than that of the etomidate group $(24.0 \%)$ $(P=0.033)$. The incidence of pain at injection site in the propofol group $(28.0 \%)$ was higher than that of the etomidate group $(0.0 \%)$ and the propofol plus etomidate group (4.0\%) $(P=0.025)$. There were no statistical differences in the PONV among all three groups. (Table 2) 


\section{Discussion}

In this prospective, randomized controlled trial comparing the effects of the combination of propofol and etomidate versus propofol or etomidate alone during induction of GA we found that the use of the combination of propofol and etomidate provided more stable BP profile with a lower incidence of pain at injection site and myoclonic movement during injection of the anesthetic agents compared with the other two groups. However, there was no statistically significant difference among three groups regarding HR change and PONV in the PACU.

Hemodynamic fluctuation during the induction of GA is a common event and an important clinical consideration for anesthesiologists $[1,8,18]$. Jor and colleagues found that hypotension after induction of GA with propofol and sufentanil was observed at $\geq 1$ of the assessed time points in $36.5 \%$ patients undergoing elective noncardiac surgery [3]. Several clinical studies have demonstrated that the hemodynamic changes during GA are independently associated with postoperative adverse outcomes such as myocardial injury, stroke, acute kidney injury, and death in patients undergoing surgery [19-22].

Many combinations of induction agents have been used in attempt to minimize these hemodynamic changes. Propofol and etomidate are two commonly used I.V. induction agents with fast onset and short duration of action. However, they have different clinical impacts and side effect profiles. Zheng and colleagues reported that the time to loss of consciousness was significantly shorter with etomidate than with propofol during GA induction. Moreover, the bispectral index (BIS) value with etomidate induction was 
lower at loss of consciousness [23]. Möller and colleagues found that propofol had more rapid onset of action than etomidate comparing the time to palpebral reflex loss and BIS 60 during a BIS-guided induction of GA [24]. Our data from the present study, however, demonstrated no significant differences in the values of PSI and SEF at all time points among the three groups. Differences in drug infusion strategy may contribute to the difference in results.

Hypotension frequently occurs during induction of GA using propofol [18]. Propofol can cause vasodilation and hypotension by decreasing sympathetic tone and systemic vascular resistance (SVR), and by exerting a direct effect on smooth muscle intracellular calcium mobilization [25, 26]. Additionally, its myocardial depressant property may be related to alterations in intrinsic myocyte contractile function, probably due to antagonisms of myocardial beta-adrenoceptors, calcium channel binding, or mitochondrial oxidative phosphorylation [27, 28]. Hug and colleagues studied the hypotension and bradycardia following propofol induction in 25,981 patients and found that the overall incidence of hypotension was $15.7 \%$, with $77 \%$ of the episodes recorded within 10 minutes of induction using propofol [18]. Similarly, our results showed that blood pressure decreased significantly at induction and 5, 10 min after intubation relative to baseline in the patients induced with propofol.

Etomidate has been suggested to have fewer changes in the hemodynamic profile and less cardiac depression [6, 29-31]. Propofol induction had a 34\% greater reduction in the area below baseline for MAP than the use of etomidate in patients undergoing cardiac surgery [29]. In patients undergoing coronary artery bypass grafting/valve 
replacement on cardiopulmonary bypass, etomidate provided more stable hemodynamic parameters in comparison with propofol during anesthesia induction [30]. Bendel and colleagues [10] evaluated the hemodynamic effects of etomidate versus propofol when the BIS reached 60 after induction in patients with severe aortic stenosis, and the results showed that propofol was twice as likely as etomidate to cause hypotension in anesthesia induction. Another study also demonstrated similar findings with more stable hemodynamic responses using etomidate anesthesia compared with propofol during endoscopic retrograde cholangiopancreatography [32]. However, the use of propofol resulted in less hypertension and tachycardia at and after intubation than etomidate during induction of GA in patients undergoing major abdominal surgery [24]. In our study, HR significantly increased during intubation and 1 minute after intubation in all three groups, and there was no significant difference regarding the percent change of HR. BP was higher at intubation and 1 min after intubation compared with baseline in the etomidate group. It has been previously reported that using a combination of etomidate and propofol for induction provided more stable hemodynamics compared with propofol or etomidate alone $[33,34]$. The results in our study indicate that administration of a propofol and etomidate combination improved BP stability without HR change compared with propofol alone during induction.

Myoclonus is a common phenomenon during etomidate induction, and the incidence is dose-dependent and reported at approximately 50\% - 80\% [12]. The cause of myoclonus is thought to be transient disinhibition of subcortical structures due to difference in cerebral blood flow. Another explanation is the difference of $\gamma$ - 
aminobutyric acid type $\mathrm{A}\left(\mathrm{GABA}_{\mathrm{A}}\right)$ receptor subunits within the central nervous system $[6,12]$. Previous studies revealed that the incidence of myoclonus can be significantly decreased by using divided doses, pre-injection of propofol, opioids, or dexmedetomidine [13, 35-37]. In our study, the incidence of myoclonus in the propofol plus etomidate group and the propofol group was $4.0 \%$, which is significantly lower than that of the etomidate group (24.0\%). The effect of propofol may have contributed to the reduced the incidence of myoclonus.

Pain at the injection site is one of the most common side effects of propofol. It has been reported that propofol injection pain occurred in $60 \%$ of untreated patients [7]. It has been suggested that the propofol activates TRPA1 channels which are involved in inflammation and pain sensation as the mechanism that may underlie pain during injection [38]. Propofol is water insoluble, and it is conventionally injected in $1 \%$ propofol formulated in $10 \%$ lipid emulsion [39]. The concentration of free propofol in the aqueous phase of the emulsion is considered to be associated with injection pain $[40,41]$. It has been reported that the modified propofol formulation containing longand medium-chain triglyceride (LCT/MCT) emulsion reduces pain on injection compared with formulations containing LCT [9, 42, 43]. Many studies focused on effective pharmacologic and nonpharmacologic approaches to prevent or alleviate propofol injection pain [44-46]. Opioids and lidocaine, either as a pretreatment or mixed with propofol, are reasonable options [9]. Our results showed that the incidence of pain at injection was $28 \%$ in the propofol group, which was significantly higher than that in the propofol plus etomidate group or the etomidate group. 
Propofol has an antiemetic property, and the antiemetic action is attributed to a decrease in 5-HT levels in the area postrema and probably through its action on the GABA receptors [47]. Some studies have demonstrated that it can effectively decrease the incidence of PONV, which is cited as a common side-effect of etomidate [14, 4850]. However, other studies found that etomidate did not increase the incidence of PONV [51, 52]. There was no statistically significant difference in the incidence of PONV in PACU among three groups in our study.

The major molecular targets mediating anesthetic effects of propofol on the central nervous system are specific $\mathrm{GABA}_{\mathrm{A}}$ receptor subtypes, and sites on the $\beta 1, \beta 2$, and $\beta 3$ subunits of the transmembrane domains are crucial for the hypnotic action of propofol [53]. Etomidate appears to produce anesthetic effects almost exclusively via actions by $\mathrm{GABA}_{\mathrm{A}}$ receptors, and the $\mathrm{GABA}_{\mathrm{A}}$ receptors containing $\beta 2$ and $\beta 3$ subunits are modulated and activated by etomidate, whereas those containing $\beta 1$ are much less affected.[6] The difference of etomidate and propofol binding site at GABA receptor provided the basis for their combination.

There are several limitations in this study. First, this randomized controlled trial recruited a relatively small number of patients drawn from a single center. Small sample size may result in Type II errors owing to low power. Multiple testing may increase the likelihood of Type 1 errors. Therefore, we selected appropriate statistical methods such as GLM and post hoc Bonferroni test to reduce the probability of statistical errors. Second, we only enrolled patients undergoing non-cardiac surgery and excluded patients with body mass index $\geq 40 \mathrm{~kg} / \mathrm{m}^{2}$ and with severe cardiopulmonary or liver 
diseases, which limits the generalizability of our results. Third, fentanyl was given during induction of GA, and this might have confounded results of the hemodynamic profile. Finally, our study focused only on the hemodynamic effects of the combination of etomidate and propofol versus propofol or etomidate alone during induction of GA. This study did not assess outcomes such as the risk of 30-day mortality which may require a larger study population and a longer study period.

In conclusion, the administration of the combination of propofol and etomidate provided more stable BP profiles without changing HR during the induction of GA. This combination also had a fewer side effects such as pain at injection site and myoclonic movements during induction compared with propofol or etomidate alone. Since the total numbers of patients is relatively small, a larger, multicenter, randomized controlled trial is warranted to further investigate and confirm these findings. 


\section{Acknowledgements}

Assistance with the study: The authors thank Ana Arias and Natasha Pineiro for their assistants on IRB submission and registration on ClinicalTrials.gov.

\section{Funding}

Financial support and sponsorship: this work was supported in part by the department of Anesthesiology and Pain Medicine, University of California Davis Health and NIH grant UL1 TR000002 of the University of California Davis Health.

Conflicts of interest: The authors declare no conflict of interest. 


\section{References}

1. Reich DL, Hossain S, Krol M, Baez B, Patel P, Bernstein A, Bodian CA. Predictors of hypotension after induction of general anesthesia. Anesth Analg 2005; 101: 622628.

2. Ida M, Kimoto K, Iwata M, Nakayama K, Kamiya T, Kuzumoto N, Shimomura T. Retrospective evaluation of predictors and frequency of hypotension in hypertensive patients after induction of general anesthesia. Masui 2014; 63: 614-618.

3. Jor O, Maca J, Koutna J, Gemrotova M, Vymazal T, Litschmannova M, Sevcik P, Reimer P, Mikulova V, Trlicova M, Cerny V. Hypotension after induction of general anesthesia: occurrence, risk factors, and therapy. A prospective multicentre observational study. J Anesth 2018; 32: 673-680.

4. Jaber S, Amraoui J, Lefrant JY, Arich C, Cohendy R, Landreau L, Calvet Y, Capdevila X, Mahamat A, Eledjam JJ. Clinical practice and risk factors for immediate complications of endotracheal intubation in the intensive care unit: a prospective, multiple-center study. Crit Care Med 2006; 34: 2355-2361.

5. Shribman AJ, Smith G, Achola KJ. Cardiovascular and catecholamine responses to laryngoscopy with and without tracheal intubation. Br J Anaesth 1987; 59: 295-299.

6. Forman SA. Clinical and molecular pharmacology of etomidate. Anesthesiology 2011; 114: 695-707.

7. Langley MS, Heel RC. Propofol. A review of its pharmacodynamic and pharmacokinetic properties and use as an intravenous anaesthetic. Drugs 1988; 35: 334-372. 
8. Kawasaki S, Kiyohara C, Tokunaga S, Hoka S. Prediction of hemodynamic fluctuations after induction of general anesthesia using propofol in non-cardiac surgery: a retrospective cohort study. BMC Anesthesiol 2018; 18: 167.

9. Jalota L, Kalira V, George E, Shi YY, Hornuss C, Radke O, Pace NL, Apfel CC, Perioperative Clinical Research C. Prevention of pain on injection of propofol: systematic review and meta-analysis. BMJ 2011; 342: d1110.

10. Bendel S, Ruokonen E, Polonen P, Uusaro A. Propofol causes more hypotension than etomidate in patients with severe aortic stenosis: a double-blind, randomized study comparing propofol and etomidate. Acta Anaesthesiol Scand 2007; 51: 284289.

11. Schraag S, Pradelli L, Alsaleh AJO, Bellone M, Ghetti G, Chung TL, Westphal M, Rehberg S. Propofol vs. inhalational agents to maintain general anaesthesia in ambulatory and in-patient surgery: a systematic review and meta-analysis. BMC Anesthesiol 2018; 18: 162.

12. Doenicke AW, Roizen MF, Kugler J, Kroll H, Foss J, Ostwald P. Reducing myoclonus after etomidate. Anesthesiology 1999; 90: 113-119.

13. Wang J, Li QB, Wu YY, Wang BN, Kang JL, Xu XW. Efficacy and Safety of Opioids for the Prevention of Etomidate-Induced Myoclonus: A Meta-Analysis. Am J Ther 2018; 25: e517-e523.

14. Yelavich PM, Holmes CM. Etomidate: a foreshortened clinical trial. Anaesth Intensive Care 1980; 8: 479-483.

15. Xue W, Li Y, Li J, Yan L, Yang F. Endothelium-dependent relaxation induced by 
etomidate in the aortas of insulin-resistant rats. Arch Med Sci 2018; 14: 1155-1162.

16. Meng QT, Cao C, Liu HM, Xia ZY, Li W, Tang LH, Chen R, Jiang M, Wu Y, Leng Y, Lee CC. Safety and efficacy of etomidate and propofol anesthesia in elderly patients undergoing gastroscopy: A double-blind randomized clinical study. Exp Ther Med 2016; 12: 1515-1524.

17. Zhou X, Li BX, Chen LM, Tao J, Zhang S, Ji M, Wu MC, Chen M, Zhang YH, Gan GS, Song XY. Etomidate plus propofol versus propofol alone for sedation during gastroscopy: a randomized prospective clinical trial. Surg Endosc 2016; 30: 51085116.

18. Hug CC, Jr., McLeskey CH, Nahrwold ML, Roizen MF, Stanley TH, Thisted RA, Walawander CA, White PF, Apfelbaum JL, Grasela TH, et al. Hemodynamic effects of propofol: data from over 25,000 patients. Anesth Analg 1993; 77: S21-29.

19. Hallqvist L, Martensson J, Granath F, Sahlen A, Bell M. Intraoperative hypotension is associated with myocardial damage in noncardiac surgery: An observational study. Eur J Anaesthesiol 2016; 33: 450-456.

20. Bijker JB, Persoon S, Peelen LM, Moons KG, Kalkman CJ, Kappelle LJ, van Klei WA. Intraoperative hypotension and perioperative ischemic stroke after general surgery: a nested case-control study. Anesthesiology 2012; 116: 658-664.

21. Sun LY, Wijeysundera DN, Tait GA, Beattie WS. Association of intraoperative hypotension with acute kidney injury after elective noncardiac surgery. Anesthesiology 2015; 123: 515-523.

22. Monk TG, Bronsert MR, Henderson WG, Mangione MP, Sum-Ping ST, Bentt DR, 
Nguyen JD, Richman JS, Meguid RA, Hammermeister KE. Association between Intraoperative Hypotension and Hypertension and 30-day Postoperative Mortality in Noncardiac Surgery. Anesthesiology 2015; 123: 307-319.

23. Zheng H, Zhu Y, Chen K, Shen X. The effect of etomidate or propofol on brainstem function during anesthesia induction: a bispectral index-guided study. Drug Des Devel Ther 2019; 13: 1941-1946.

24. Moller Petrun A, Kamenik M. Bispectral index-guided induction of general anaesthesia in patients undergoing major abdominal surgery using propofol or etomidate: a double-blind, randomized, clinical trial. Br J Anaesth 2013; 110: 388396.

25. Chang KS, Davis RF. Propofol produces endothelium-independent vasodilation and may act as a Ca2+ channel blocker. Anesth Analg 1993; 76: 24-32.

26. Ebert TJ, Muzi M, Berens R, Goff D, Kampine JP. Sympathetic responses to induction of anesthesia in humans with propofol or etomidate. Anesthesiology 1992; 76: 725-733.

27. Zhou W, Fontenot HJ, Wang SN, Kennedy RH. Propofol-induced alterations in myocardial beta-adrenoceptor binding and responsiveness. Anesth Analg 1999; 89: 604-608.

28. Zhou W, Fontenot HJ, Liu S, Kennedy RH. Modulation of cardiac calcium channels by propofol. Anesthesiology 1997; 86: 670-675.

29. Hannam JA, Mitchell SJ, Cumin D, Frampton C, Merry AF, Moore MR, Kruger CJ. Haemodynamic profiles of etomidate vs propofol for induction of anaesthesia: a 
randomised controlled trial in patients undergoing cardiac surgery. Br J Anaesth 2019; 122: 198-205.

30. Kaushal RP, Vatal A, Pathak R. Effect of etomidate and propofol induction on hemodynamic and endocrine response in patients undergoing coronary artery bypass grafting/mitral valve and aortic valve replacement surgery on cardiopulmonary bypass. Ann Card Anaesth 2015; 18: 172-178.

31. Baradari AG, Alipour A, Habibi MR, Rashidaei S, Emami Zeydi A. A randomized clinical trial comparing hemodynamic responses to ketamine-propofol combination (ketofol) versus etomidate during anesthesia induction in patients with left ventricular dysfunction undergoing coronary artery bypass graft surgery. Arch Med Sci 2017; 13: 1102-1110.

32. Song JC, Lu ZJ, Jiao YF, Yang B, Gao H, Zhang J, Yu WF. Etomidate Anesthesia during ERCP Caused More Stable Haemodynamic Responses Compared with Propofol: A Randomized Clinical Trial. Int J Med Sci 2015; 12: 559-565.

33. Hosseinzadeh H, Golzari SE, Torabi E, Dehdilani M. Hemodynamic Changes following Anesthesia Induction and LMA Insertion with Propofol, Etomidate, and Propofol + Etomidate. J Cardiovasc Thorac Res 2013; 5: 109-112.

34. Yagan O, Tas N, Kucuk A, Hanci V, Yurtlu BS. Haemodynamic Responses to Tracheal Intubation Using Propofol, Etomidate and Etomidate-Propofol Combination in Anaesthesia Induction. J Cardiovasc Thorac Res 2015; 7: 134-140. 35. Aissaoui Y, Belyamani L, El Wali A, Idrissi Hajjouji SM, Atmani M, Drissi Kamili N. Prevention of myoclonus after etomidate using a priming dose. Ann Fr Anesth 
Reanim 2006; 25: 1041-1045.

36. Du X, Zhou C, Pan L, Li C. Effect of dexmedetomidine in preventing etomidateinduced myoclonus: a meta-analysis. Drug Des Devel Ther 2017; 11: 365-370.

37. Liu J, Liu R, Meng C, Cai Z, Dai X, Deng C, Zhang J, Zhou H. Propofol decreases etomidate-related myoclonus in gastroscopy. Medicine (Baltimore) 2017; 96: e7212.

38. Matta JA, Cornett PM, Miyares RL, Abe K, Sahibzada N, Ahern GP. General anesthetics activate a nociceptive ion channel to enhance pain and inflammation. Proc Natl Acad Sci USA 2008; 105: 8784-8789.

39. Baker MT, Naguib M. Propofol: the challenges of formulation. Anesthesiology 2005; 103: 860-876.

40. Doenicke AW, Roizen MF, Rau J, O'Connor M, Kugler J, Klotz U, Babl J. Pharmacokinetics and pharmacodynamics of propofol in a new solvent. Anesth Analg 1997; 85: 1399-1403.

41. Rau J, Roizen MF, Doenicke AW, O'Connor MF, Strohschneider U. Propofol in an emulsion of long- and medium-chain triglycerides: the effect on pain. Anesth Analg 2001; 93: 382-384

42. Allford MA, Mensah JA. Discomfort on injection: a comparison between two formulations of propofol. Eur J Anaesthesiol 2006; 23: 971-974.

43. Lee JS, Kim ES, Cho KB, Park KS, Lee YJ, Lee JY. Pain Intensity at Injection Site during Esophagogastroduodenoscopy Using Long- and Medium-Chain versus LongChain Triglyceride Propofol: A Randomized Controlled Double-Blind Study. Gut Liver 2020, 10.5009/gnl20243 
44. Kim K, Sung Kim Y, Lee DK, Lim BG, Kim HZ, Kong MH, Kim NS, Lee IO. Reducing the pain of microemulsion propofol injections: a double-blind, randomized study of three methods of tourniquet and lidocaine. Clin Ther 2013; 35: 1734-1743.

45. Shimizu T, Inomata S, Tanaka M. Rapid injection of propofol reduces vascular pain and facilitates Laryngeal Mask Airway insertion. J Clin Anesth 2011; 23: 540-543.

46. Honarmand A, Safavi M. Prevention of propofol-induced injection pain by sufentanil: a placebo-controlled comparison with remifentanil. Clin Drug Investig $2008 ; 28: 27-35$.

47. Cechetto DF, Diab T, Gibson CJ, Gelb AW. The effects of propofol in the area postrema of rats. Anesth Analg 2001; 92: 934-942.

48. Soppitt AJ, Glass PS, Howell S, Weatherwax K, Gan TJ. The use of propofol for its antiemetic effect: a survey of clinical practice in the United States. J Clin Anesth 2000; 12: 265-269.

49. Celik M, Dostbil A, Aksoy M, Ince I, Ahiskalioglu A, Comez M, Erdem AF. Is infusion of subhypnotic propofol as effective as dexamethasone in prevention of postoperative nausea and vomiting related to laparoscopic cholecystectomy? A randomized controlled trial. Biomed Res Int 2015; 2015: 349806.

50. Niu K, Liu H, Chen RW, Fang QW, Wen H, Guo SM, Williams JP, An JX. Use of propofol for prevention of post-delivery nausea during cesarean section: a doubleblind, randomized, placebo-controlled trial. J Anesth 2018; 32: 748-755.

51. St Pierre M, Dunkel M, Rutherford A, Hering W. Does etomidate increase postoperative nausea? A double-blind controlled comparison of etomidate in lipid 
emulsion with propofol for balanced anaesthesia. Eur J Anaesthesiol 2000; 17: 634641.

52. Ye L, Xiao X, Zhu L. The Comparison of Etomidate and Propofol Anesthesia in Patients Undergoing Gastrointestinal Endoscopy: A Systematic Review and MetaAnalysis. Surg Laparosc Endosc Percutan Tech 2017; 27: 1-7.

53. Krasowski MD, Koltchine VV, Rick CE, Ye Q, Finn SE, Harrison NL. Propofol and other intravenous anesthetics have sites of action on the gamma-aminobutyric acid type A receptor distinct from that for isoflurane. Mol Pharmacol 1998; 53: 530-538. 


\section{Legends}

Figure 1. CONSORT flow diagram of the study. Group PE, Etomidate plus propofol group; Group E, Etomidate group; Group P, propofol group.

Figure 2. Hemodynamic variables during the induction. Group PE, Etomidate plus propofol; Group E, Etomidate; Group P, propofol. HR, Heart rate; SBP, systolic blood pressure; DBP, diastolic blood pressure; MAP, mean arterial pressure; bpm, beats per min. T0, baseline; T1, induction; T2, intubation; T3-T6, 1, 3, 5, 10 min after intubation. Data are expressed as mean \pm SD. ${ }^{\#} P<0.05,{ }^{\# \#} P<0.01$ with respect to baseline; ${ }^{* *} P<$ $0.01,{ }^{*} P<0.05$ with respect to the group $\mathrm{P}$.

Figure 3. Processed EEG values during the induction. Group PE, Etomidate plus propofol; Group E, Etomidate; Group P, propofol. PSI, patient state index; SEFL, spectral edge frequency left; SEFR, spectral edge frequency right. Data are expressed as mean $\pm \mathrm{SD} .{ }^{\sharp} P<0.01$ with respect to baseline.

Figure 4. Time course of percent change in heart rate (HR), systolic blood pressure (SBP), diastolic blood pressure (DBP) and mean arterial pressure (MAP). Group PE, Etomidate plus propofol; Group E, Etomidate; Group P, propofol. Data are expressed as mean $\pm \mathrm{SD} .{ }^{\#} P<0.05$ between group $\mathrm{PE}$ and group $\mathrm{P} ;{ }^{\&} P<0.05$ between group $\mathrm{E}$ and group $\mathrm{P}$. 
Table 1. Clinical characteristics of the patients in the study (per group $n=25$ )

\begin{tabular}{lllll}
\hline & Group PE & Group E & Group P & $P$ \\
\hline Age (years) & $61.4 \pm 11.6$ & $62.5 \pm 14.7$ & $61.2 \pm 8.5$ & 0.915 \\
Sex (F/M) & $12 / 13$ & $13 / 12$ & $14 / 11$ & 0.852 \\
BMI (kg/m $\left.{ }^{2}\right)$ & $29.9 \pm 5.2$ & $27.5 \pm 5.1$ & $29.7 \pm 5.6$ & 0.211 \\
ASA physical status, $\mathrm{n}$ & & & & 0.664 \\
2 & 22 & 22 & 20 & \\
3 & 3 & 3 & 5 & 0.907 \\
Mallampati class, $\mathrm{n}$ & & & 13 & \\
1 & 15 & 16 & 10 & \\
2 & 9 & 8 & 2 & \\
3 & 1 & 1 & & \\
\hline
\end{tabular}

The data were presented with mean \pm SD or numbers. There were no significant differences among the three groups. Group PE, Etomidate plus propofol; Group E, Etomidate; Group P, propofol. 
Table 2. Incidence of myoclonus, pain at injection site, and PONV in three groups

\begin{tabular}{lllll}
\hline & Group PE & Group E & Group P & $P$ \\
\hline Myoclonus, n & & & & 0.033 \\
0 & 24 & 19 & 24 & \\
1 & 1 & 0 & 1 & \\
2 & 0 & 4 & 0 & 0.025 \\
3 & 0 & 2 & 0 & \\
Pain at injection, n & & & & \\
0 & 24 & 25 & 18 & \\
1 & 1 & 0 & 3 & 0.353 \\
2 & 0 & 0 & 3 & \\
3 & 0 & 0 & 0 & \\
\hline
\end{tabular}

The data were presented with numbers. Group PE, Etomidate plus propofol; Group E,

Etomidate; Group P, propofol. PONV, postoperative nausea and vomiting. 


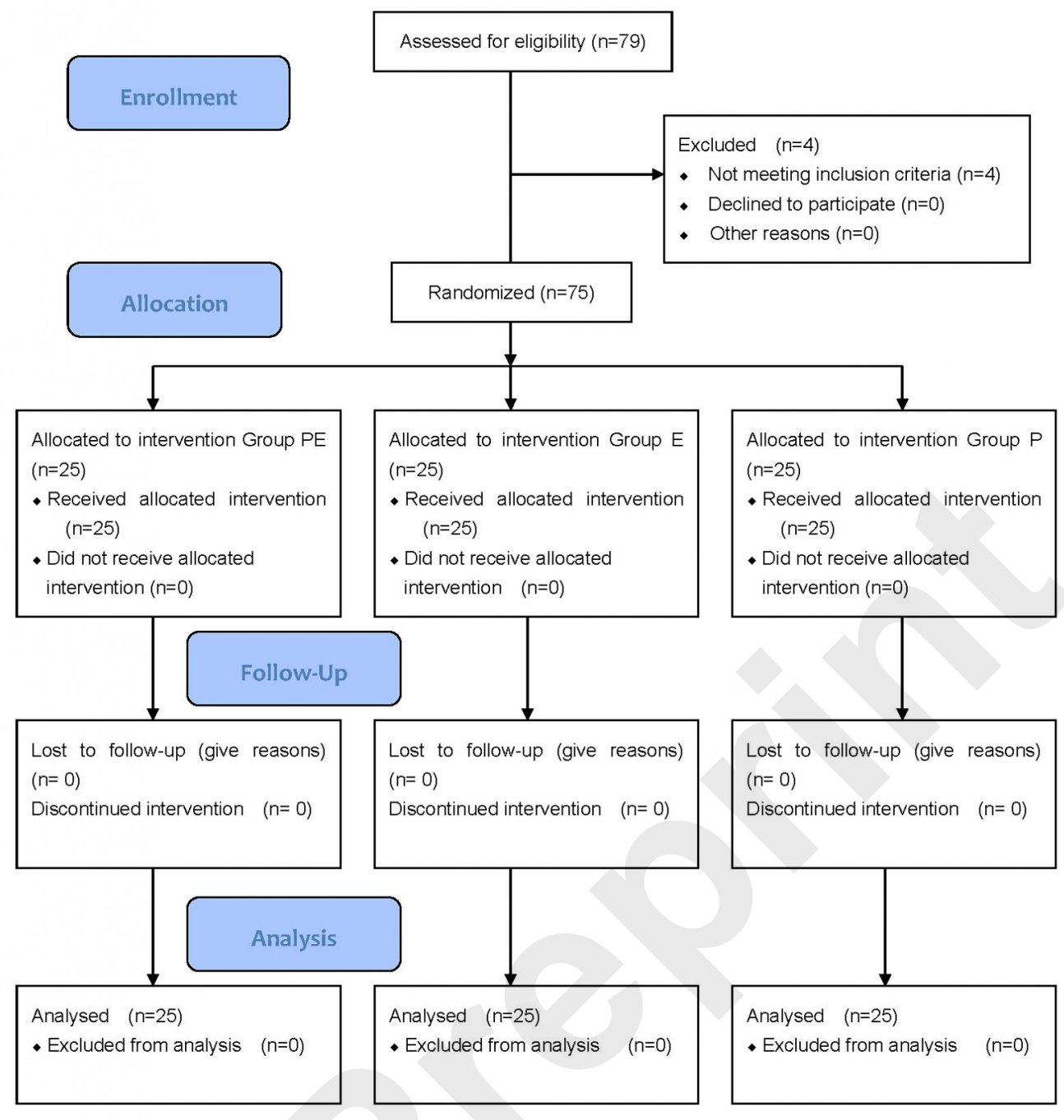

Figure 1. CONSORT flow diagram of the study. Group PE, Etomidate plus propofol group; Group E, Etomidate group; Group P, propofol group. 

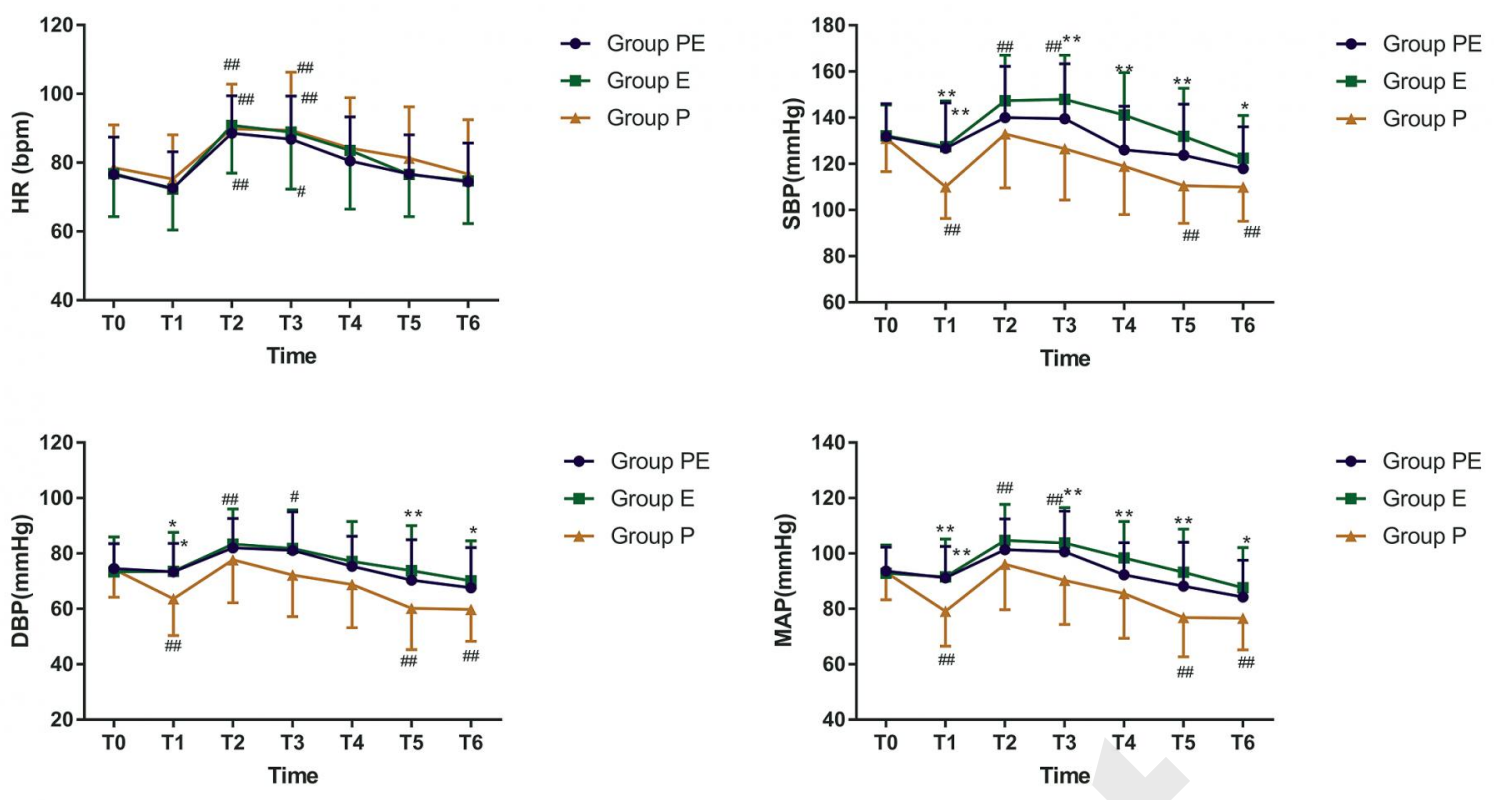

Figure 2. Hemodynamic variables during the induction. Group PE, Etomidate plus propofol; Group E, Etomidate; Group P, propofol. HR, Heart rate; SBP, systolic blood pressure; DBP, diastolic blood pressure; MAP, mean arterial pressure; bpm, beats per min. T0, baseline; T1, induction; T2, intubation; T3-T6, 1, 3, 5, 10 min after intubation. Data are expressed as mean $\pm \mathrm{SD}$. \#P $\square 0.05$, \#\# $\mathrm{P} \square 0.01$ with respect to baseline; ${ }^{*} \mathrm{P} \square 0.01$, ${ }^{*} \mathrm{P} \square 0.05$ with respect to the group $P$. 


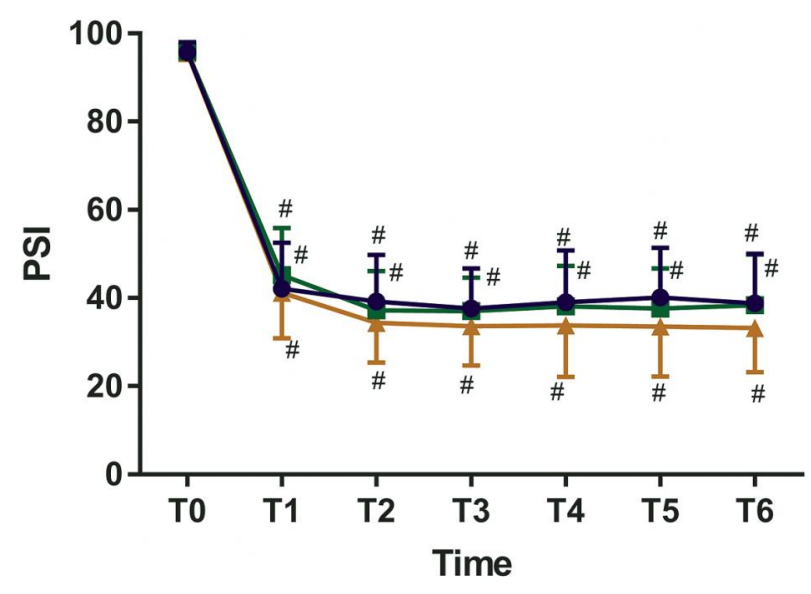

$$
\begin{aligned}
& \rightarrow \text { Group PE } \\
& \rightarrow \text { Group E } \\
& + \text { Group P }
\end{aligned}
$$
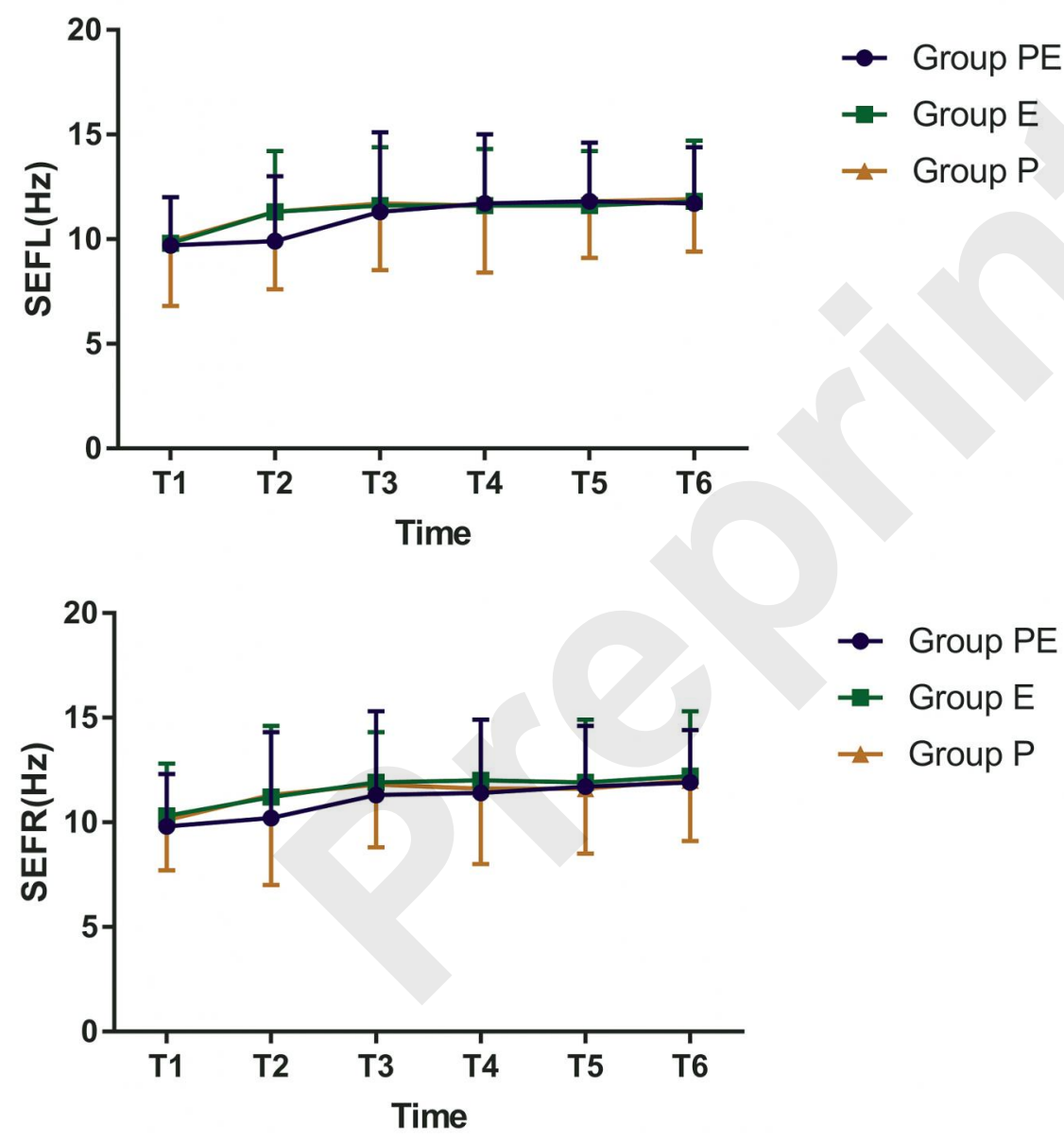

Figure 3. Processed EEG values during the induction. Group PE, Etomidate plus propofol; Group E, Etomidate; Group P, propofol. PSI, patient state index; SEFL, spectral edge frequency left; SEFR, spectral edge frequency right. Data are expressed as mean \pm SD. $\# \mathrm{P} \square 0.01$ with respect to baseline. 

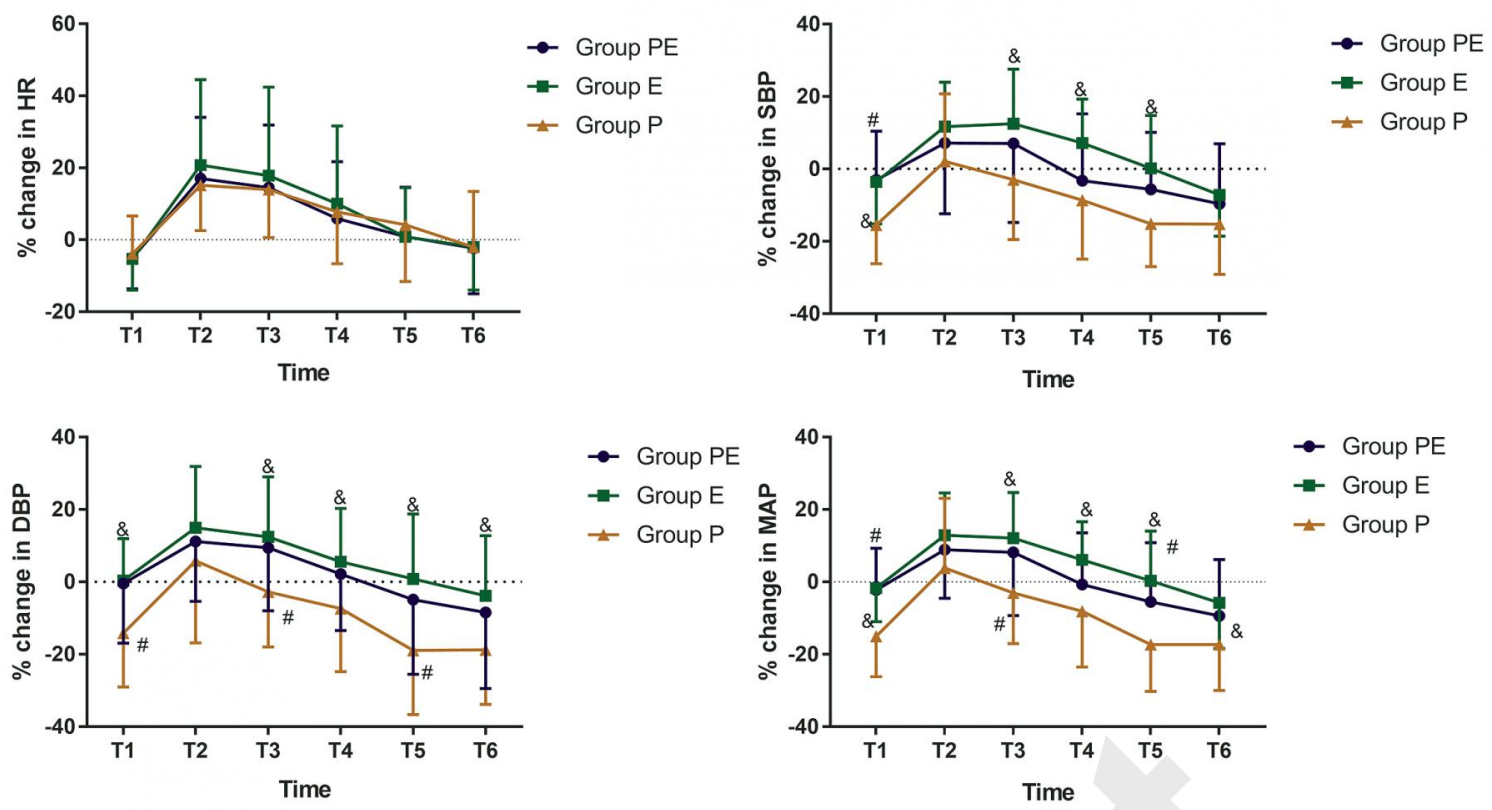

Figure 4. Time course of percent change in heart rate (HR), systolic blood pressure (SBP), diastolic blood pressure (DBP) and mean arterial pressure (MAP). Group PE, Etomidate plus propofol; Group E, Etomidate; Group P, propofol. Data are expressed as mean \pm SD. \#P $\square 0.05$ between group PE and group $P ; \square P \square 0.05$ between group $E$ and group $P$. 